\title{
An Investigation Of The Impact Of Fouling Agents In Capacitive And Membrane
} Capacitive Deionisation

(1)

(1)

${ }^{\mathrm{b}}$ The ARC Dairy Innovation Hub, Department of Chemical Engineering, University of (1)

*Corresponding Author: Melbourne, Parkville, VIC 3010, Australia

\author{
A. Hassanvand ${ }^{\mathrm{a}}$, G. Q. Chen ${ }^{\mathrm{a}, \mathrm{b}}$, P. A. Webley ${ }^{\mathrm{a}}$, S. E. Kentish ${ }^{\mathrm{a}, \mathrm{b}, *}$
}

a Department of Chemical Engineering, University of Melbourne, Parkville, VIC 3010, Australia

E-mail address: sandraek@unimelb.edu.au (S.E.Kentish).

Postal address: School of Chemical and Biomedical Engineering, The University of Melbourne, Parkville, 3010 Victoria, Australia

Tel.: +61383446682.

\section{Abstract}

The effect of organic fouling on both capacitive deionization (CDI) and membrane capacitive deionization (MCDI) was studied using two model foulants, the sodium salt of alginic acid and humic acid. Fouling of the activated carbon electrodes in the CDI cell was significant. The salt adsorption fell to $75 \%$ and the charge efficiency to $90 \%$ of their initial values after 18 cycles of operation with $0.5 \mathrm{mM} \mathrm{CaCl}_{2}$ and $60 \mathrm{mg} \mathrm{L}^{-1}$ of sodium alginate. Similarly, the salt adsorption fell to $70 \%$ and the charge efficiency to $65 \%$ of their initial values after 18 cycles of operation with $60 \mathrm{mg} \mathrm{L}^{-1}$ of humic acid. The effect on MCDI was much more limited with these two foulants. The ability to clean the CDI cell with alkali cleaning agents was also investigated. While this cleaning was effective in restoring the salt adsorption, the alkali solution caused erosion of the activated carbon electrode or its PVDF binder, evidenced by an accumulation of carbon within the cleaning solution. Alternative electrode designs or alternative cleaning solutions will be needed if this approach is to be used in systems with similar foulants.

Keywords: desalination; sodium alginate; humic acid; PVDF. 


\section{Introduction}

30 Capacitive Deionisation (CDI) and Membrane capacitive Deionisation (MCDI) are emerging desalination technologies which have shown promise for the removal of a range of salts from solutions of concentration less than $2 \mathrm{~g} /$ litre [1]. However, less effort has been made to investigate the effect of fouling in these systems. Although these processes operate at low salinity, organic matter may still be present. These organic foulants can unfavourably attach to the surface of the carbon material or the ion exchange membranes in these processes.

The degree of fouling depends on both the foulant and absorbent. The concentration, surface charge, molecular weight, functional groups, and tendency towards agglomeration of the foulants are important. On the other hand, the properties of the carbon including pore structure and size distribution, surface area, functional groups, bulk density and ash content play a role in fouling of the carbon surface [2-4]. For example, Mossad et al. [5] reported a fall in salt removal efficiency and feed flowrate over 30 hours of operation, when a sodium salt of humic acid was present during CDI processing. They found that the presence of calcium or magnesium had little effect on this performance, although ferric ions appeared to have some impact. Extended trials of this approach on a brackish water stream confirmed that calcium and magnesium salts caused little change in performance in the absence of organic matter and that the presence of silica was also not detrimental[6]. Conversely, when an alternate stream with a significant concentration of dissolved organics $(2 \mathrm{mg} / \mathrm{L})$ was tested, the salt removal efficiency declined.

Similarly, the membrane charge is of great importance in determining whether an ion exchange membrane will be prone to fouling during MCDI [7-10]. Chen et al.[11] observed fouling of an MCDI unit over 15 days with a feed of $75 \mathrm{mg} / \mathrm{L} \mathrm{NaCl}$ or $65.5 \mathrm{mg} / \mathrm{L} \mathrm{CaCl}_{2}$ and either humic acid or sodium alginate as the foulant. These authors observed a clear decline in both energy efficiency and salt removal efficiency, which they attributed to the negative charge of the foulant driving it to the relevant membrane when an electrical charge was applied. Kim et al. [12] observed a decrease in salt removal efficiency when 5 and $10 \mathrm{mg} \mathrm{L}^{-1}$ of octane was added to a solution of $17 \mathrm{mM} \mathrm{NaCl}$, in the first 6 cycles of operation. However, the operation stabilised in the following four cycles, which was attributed to the octane reaching an adsorption equilibrium on the IEM surface.

To date, no research group has done a comprehensive study comparing the effect of fouling in 
this paper, the extent of fouling in CDI and MCDI has been studied using two high molecular weight organic model foulants, sodium salt of alginic acid (SA) and sodium salt of humic acid (HA). The salt adsorption capacity and the charge efficiency of the cell are the two metrics selected to navigate the desalination performance of the (M)CDI cell. To better understand the role of carbon and the IEMs in fouling, MCDI performance before, during and after fouling has been compared with that of CDI. The performance of potential cleaning agents to remove the fouled layer is investigated. The experiments have been done in a single-pass mode and for at least 6 hours of fouling and thus give an insight to the detrimental effect of fouling on CDI and MCDI at a larger scale.

\section{Materials and Methods}

\subsection{Materials}

The CDI cell consisted of two parallel electrodes separated by a non-conductive spacer (Low Foulant spacer 34 mil, Sterlitech). Activated carbon electrodes were prepared from activated carbon (AC Norit SA 4, $\mathrm{D}_{50}=30 \mu \mathrm{m}$, Cabot Norit Activated Carbon, USA), N-N dimethylformamide (DMF, 99.8\%, Merck Millipore) and polyvinylidene fluoride (PVDF, Mw $\sim 530,000 \mathrm{~g} \mathrm{~mol}^{-1}$, Sigma-Aldrich) as previously described [13]. A graphite sheet (DSN 530, Suzhou Dasen Electronics Material Co.) was used as the current collector. Commercially available anion and cation-exchange membranes (Neosepta AMX, thickness of $170 \mu \mathrm{m}$, and Neosepta CMX, thickness of $140 \mu \mathrm{m}$ ) were used to build the MCDI cell.

The electrical voltage was applied by a DC power module (N6731B- 5 V, 10 A, Agilent) in a modular power system mainframe (N6700- $400 \mathrm{~W}$, Agilent). The electrical current across the cell was recorded through using either LabVIEW software or BenchVue software provided by the supplier.

Sodium chloride $\left(\mathrm{NaCl}, 99.7 \%\right.$, ChemSupply) and calcium chloride $\left(\mathrm{CaCl}_{2}, 99 \%\right)$ were used to prepare salt solutions. Sodium hydroxide $(\mathrm{NaOH}, 97.0 \%$, ChemSupply) and hydrochloric acid ( $\mathrm{HCl}, 37.0 \%$, ChemSupply) were used for CDI cell cleaning. Solutions were prepared using water with electrical resistance of $1 \mathrm{M} \Omega \mathrm{cm}^{-1}$ (Millipore RIOs Large).

Alginic acid sodium salt from brown algae $\left(\mathrm{M}_{\mathrm{w}} 12-80 \mathrm{kDa}\right)$ and humic acid sodium salt were purchased in powder form from Sigma Aldrich as the model organic foulants. Sodium alginate (SA) is a polysaccharide produced by marine microorganisms [14]. It is a linear copolymer 
consisting of irregular, but not generally random, repeating blocks of $\beta$-D-mannuronic acid and $\alpha$-L-guluronic acid which is often used to represent high molecular weight hydrophilic biopolymer foulants $[15,16]$. To better understand the fouling behaviour of alginic acid present in wastewater, calcium was added to the fouling feed containing alginic acid. A stable macromolecular structure is formed upon the addition of calcium, as $\mathrm{Na}^{+}$ions in SA solution is substituted by $\mathrm{Ca}^{2+}$ [17]. Calcium cross-links through the carboxylate groups of mannuronic and guluronic acids of SA, which then leads to the formation of gel/colloids [18]. In cases where calcium chloride was added to the feed, the concentration of the $\mathrm{NaCl}$ solution was adjusted to maintain the total ionic strength of the feed constant.

Humic acid (HA) is a natural hydrophobic macromolecular organic compound (500-250,000 $\mathrm{Da}[2])$ which can be found in river, lake and pond water [19, 20]. Within the HA structure, carboxyl, phenolic and aliphatic hydroxyl functional groups build the core components while alkali metals associate with humic molecules through ion-exchange reactions [21, 22].

\subsection{Methods}

Experiments were carried out in single-pass mode, where the conductivity and $\mathrm{pH}$ of the effluent is measured after it leaves the CDI or MCDI cell. The desalination of the clean (unfouled) unit was first evaluated with $10 \mathrm{mM} \mathrm{NaCl}$ solution. Adsorption was conducted over a 10 minute cycle time at a constant voltage of $1.5 \mathrm{~V}$, while a 10 minute desorption cycle followed at zero voltage in CDI and a reversed polarity of $-1.5 \mathrm{~V}$ in MCDI. Adsorption/desorption cycles were conducted until consistent behaviour was observed between each cycle. However, only the last three adsorption/desorption cycles are presented here. This step is referred to as the 'before-fouling' stage.

113 Following this, the fouling stage was carried out using a salt solution of $10 \mathrm{mM}$ ionic strength, 114 containing organic foulant at different concentrations. This stage continued for at least 18 115 adsorption/desorption cycles. The first cycle is not included in the results shown due to the 116 effect of the previous stage. Therefore, the data presented covers cycles 2 to 18 , representing a 117 fouling period of 6 hours.

118 At the end of the fouling stage, the post-fouling performance of the fouled cell was studied by 119 measuring the (M)CDI metrics with a clean $10 \mathrm{mM} \mathrm{NaCl}$ solution. This step is referred to as the 'after-fouling' stage. In cases where cleaning was employed, the cleaning solution was then 
121 pumped through the cell for a certain time. Then the performance of the cleaned cell was quantified again with $10 \mathrm{mM} \mathrm{NaCl}$ solution.

123 The $\mathrm{pH}$ of the feed containing organic foulant was not adjusted, unless specified. Selected

124 fouling runs were duplicated to confirm reproducibility within a 5\% error margin. All the 125 experiments were performed at room temperature.

126 The salt adsorption (Q') represents the total amount of charged species removed during the 127 adsorption step per gram of carbon mass in the electrodes. This parameter is determined form 128 the conductivity $(\kappa)$ of the feed and effluent stream over a single adsorption cycle of time $t_{\text {ads }}$ 129 as shown in Equation 1.

$$
Q^{\prime}=\frac{\left(\int_{0}^{t_{\text {ads }}}\left(\kappa_{\text {feed }}-\kappa_{t}\right) \cdot d t\right) \cdot \dot{V}}{M_{\text {carbon }}}
$$

130 where $\dot{V}$ is the volumetric flow rate and $\mathrm{M}_{\text {carbon }}$ is the mass of carbon in an electrode. As 131 conductivity is used, it is not possible to distinguish between adsorption of simple ions $\left(\mathrm{Na}^{+}\right.$, $132 \mathrm{Ca}^{2+}, \mathrm{Cl}^{-}$) and that of charged foulants such as alginate or humate. However, given the high 133 molecular weight of the foulant species, it can be assumed that the major contributors to the 134 salt adsorption parameter are the ions. The values for $Q^{\prime}$ are reported as a ratio to that of the clean cell prior to the fouling test, $\mathrm{Q}_{0}^{\prime}$.

136 The charge consumption $(\sigma)$ is determined by integrating the electrical current $\left(\mathrm{I}_{\mathrm{e}}\right)$ through the 137 cell over the same adsorption cycle;

$$
\sigma=\int_{0}^{t_{a d s}} I_{e}(t) \cdot d t
$$

138 The charge efficiency $(\Lambda)$ is usually defined as the moles of salts adsorbed or released per 139 moles of electron transferred. Given the complex salt/foulant mixture used in the present case, 140 it was not possible to determine the absolute number of moles of salt adsorbed from the 141 conductivity. Hence, we report here only a pseudo charge efficiency relative to that of an 142 unfouled, clean cell i.e. 


$$
\Lambda / \Lambda_{\mathrm{o}}=\frac{\mathrm{Q}^{\prime} / \mathrm{Q}_{\mathrm{o}}^{\prime}}{\sigma / \sigma_{o}}
$$

143 The total organic carbon (TOC) content of the samples was measured using a Total Organic

144 Analyser (TOC-VCSH, SHIMADZU, Japan).

\section{Results and discussion}

\section{$147 \quad 3.1 \quad$ Fouling in CDI}

148 For both humic acid and alginic acid foulants, the salt adsorption (Q') and the charge efficiency

$149(\Lambda)$ of CDI generally fell throughout the fouling cycle (Figure 1). Covalent bonding and 150 electrostatic bonding are believed to be the dominant interactions between the organic foulants 151 and the activated carbon. In particular, in the case of a porous substance such as activated carbon, adsorption of organic compounds occurs at pores with similar diameter to the size of the adsorbent. However, in both cases, a cyclical behaviour was observed, suggesting that fouling was being adsorbed in one adsorption/desorption cycle and then being released in the next. Due to the presence of functional groups on the carbon surface such as $-\mathrm{COOH},-\mathrm{OH}$ and $-\mathrm{NH}_{2}$, the attachment of the organic species and carbon gradually increases over the 18 fouling cycles [23].

158 The results are similar to that reported by Mossad et al. [5] for SA fouling, although they used 159 a lower SA concentration $\left(10 \mathrm{mg} \mathrm{L}^{-1}\right)$ and the fouling period was extended to $30 \mathrm{~h}$. Despite the 160 fact that the hydroxyl and carboxylate functional groups of SA give it a hydrophilic character, 161 counterintuitively, it has been reported that SA adheres to hydrophobic membrane surfaces as well $[24,25]$. Stewart et al. [25] attributed this amphiphilic behaviour to the special structure of the $M$ monomers within the SA polymer sequence. M monomers feature hydrophobic and

164 hydrophilic faces on the opposite surfaces. Additionally, the enzyme behind the production of 165 SA is believed to be involved in the hydrophobic interactions. The interaction between SA and 166 activated carbon, therefore, can be justified. 

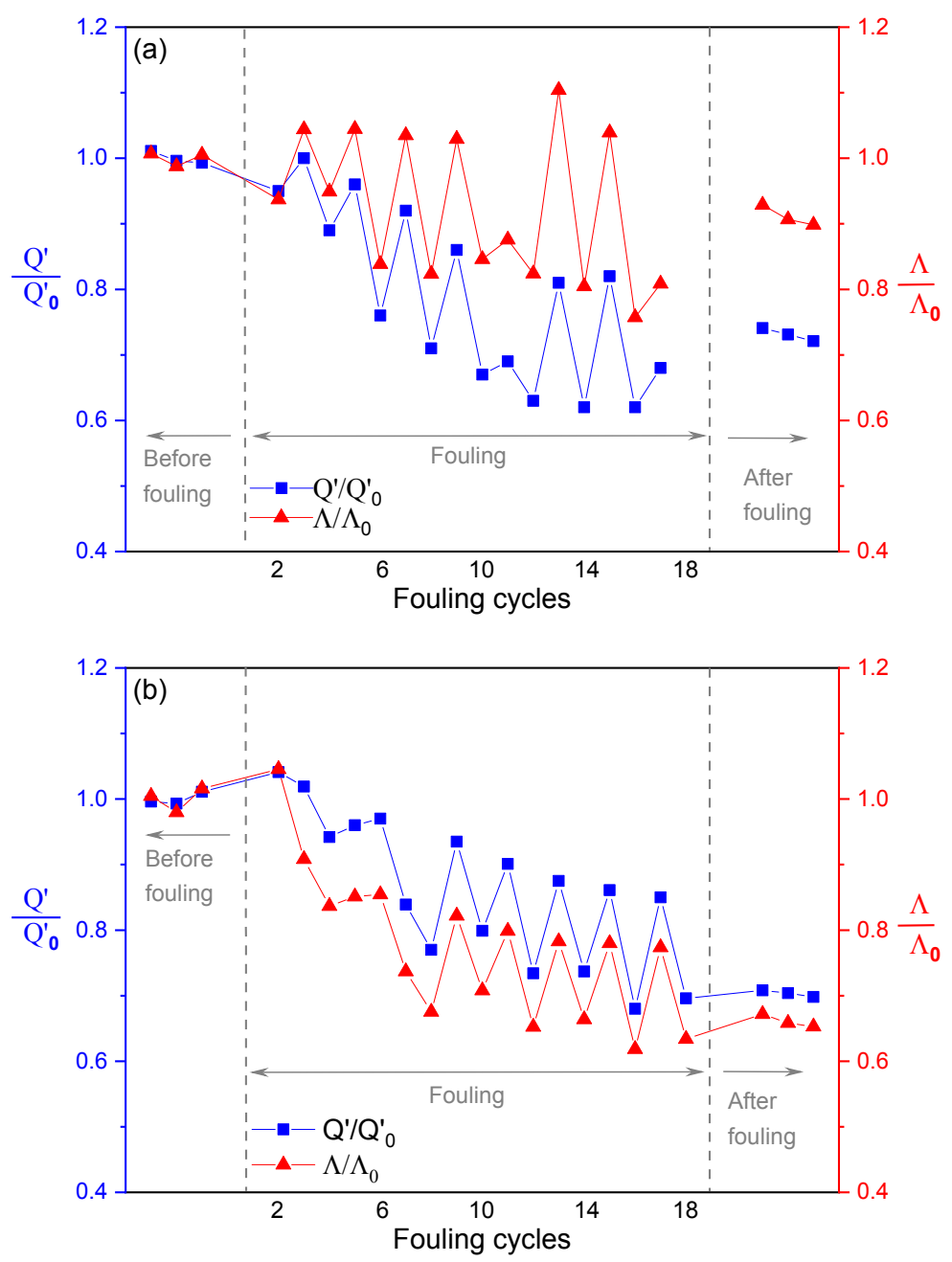

Fig. 1. The salt adsorption $\left(\mathbf{Q}^{\prime} / \mathbf{Q}_{\mathbf{0}}{ }_{\mathbf{0}}\right)$ and the charge efficiency $\left(\boldsymbol{\Lambda} / \boldsymbol{\Lambda}_{\mathbf{0}}\right)$ as a ratio to performance parameters of the clean CDI cell. Fouling was carried out with a feed containing (a) $8.5 \mathrm{mM} \mathrm{NaCl}$, $0.5 \mathrm{mM} \mathrm{CaCl}_{2}$, and $60 \mathrm{mg} \mathrm{L}^{-1}$ of SA and (b) $10 \mathrm{mM} \mathrm{NaCl}$ and $60 \mathrm{mg} \mathrm{L}^{-1}$ of $\mathrm{HA}$.

172 Mossad et al. [5] reported that the flow rate starts to decay noticeably after around 8 to $10 \mathrm{~h}$ of

173 fouling depending on the feed composition and concentration [5]. In the CDI fouling studies

174 reported here, the flow rate decrease over the 6 hour fouling period was difficult to detect within

175 the experimental error margin, with a maximum of $6.5 \pm 1.0 \%$.

176 The behaviour is subtly different for the two foulants. For SA, the salt adsorbed per cycle falls

177 further than the charge efficiency. This suggests that while there is less carbon surface available

178 for adsorption due to fouling, the fouling layer is conductive and hence the electrical charge can be readily transmitted. This may be related to the integration of calcium within this fouling 
180 system. Conversely, the charge efficiency falls further than the salt adsorption for HA, 181 suggesting that the fouling layer is providing additional resistance to the movement of electrical 182 charge.

183 For both systems, there is a net loss in performance after the foulant is removed and fresh $\mathrm{NaCl}$

184 is used, indicating that there is a need for cleaning. This loss of performance can be attributed

185 to a loss of surface area due to pore blockage, a decrease in the available adsorption sites, and

186 a change in surface charge due to the presence of the organic compounds $[5,22]$.

187 It is worth noting that the duration of fouling was limited in these laboratory investigations to

188 perform the experiments in one working day. In industrial applications, however, this step will

189 be prolonged. It can be predicted from the outcome of these experiments that CDI desalination 190 performance will deteriorate significantly in the presence of any organic foulant.

\section{$191 \quad 3.2 \quad$ Comparing MCDI and CDI}

192 Similar experiments were performed using the MCDI cell (Figure 2). It is apparent that both 193 the salt adsorption and the charge efficiency are more stable with the presence of the ion194 exchange membranes in front of the carbon electrodes. For both sodium alginate and humic 195 acid fouling, there are minimal changes in the salt adsorption. The fall in this parameter after 196 the sodium alginate fouling run may be simply due the replacement of calcium with sodium 197 ions within the IEMs. It is anticipated that this performance would return to that of the clean 198 cell over more cycles of adsorption and desorption. The charge efficiency is unchanged for 199 both sodium alginate and humic acid fouling. 

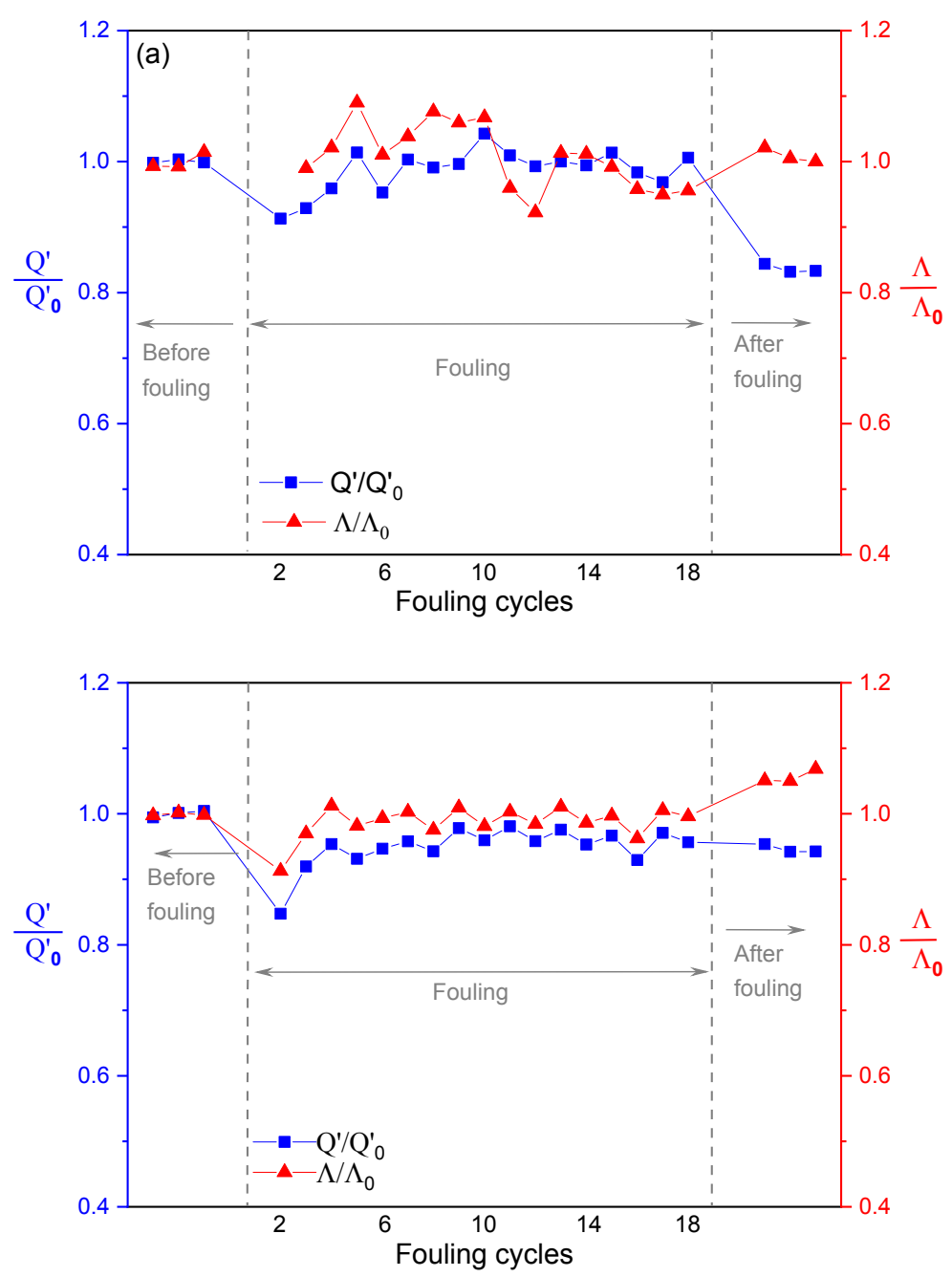

Fig. 2 The salt adsorbed $\left(Q^{\prime} / Q^{\prime}{ }_{0}\right)$ and the charge efficiency $\left(\Lambda / \Lambda_{0}\right)$ as a ratio to performance parameters of the clean cell in MCDI. Fouling was carried out with a feed containing (a) $8.5 \mathrm{mM}$ $\mathrm{NaCl}, 0.5 \mathrm{mM} \mathrm{CaCl}_{2}$, and $60 \mathrm{mg} \mathrm{L}^{-1}$ of SA and (b) $10 \mathrm{mM} \mathrm{NaCl}$ and $60 \mathrm{mg} \mathrm{L}^{-1}$ of $\mathrm{HA}$.

207 The salt removal of MCDI did not drop as noticeably in our study as it did in the work 208 performed by $\mathrm{Kim}$ et al. [11, 12]. The main reason for this discrepancy can be the small 209 molecular weight of the organic foulant used in their study, octane, in comparison with the 210 model foulants of high molecular weights used in our work. The octane may have easily 211 penetrated the membrane structure itself. 
212 During the 18 cycles of fouling, the effluent was collected in every second cycle in separate 213 containers, i.e. adsorption and desorption of cycles 2 , 4, etc. Then the average concentration of 214 organic carbon in each interval was obtained by TOC analysis. The TOC of samples collected 215 in MCDI showed very similar concentration in the effluent streams to that of the feed during 216 adsorption and desorption intervals. In comparison, there is a significant loss of organic carbon 217 during CDI experiments (see Fig. 3). This again suggest that fouling is more significant in CDI 218 than in MCDI.

219
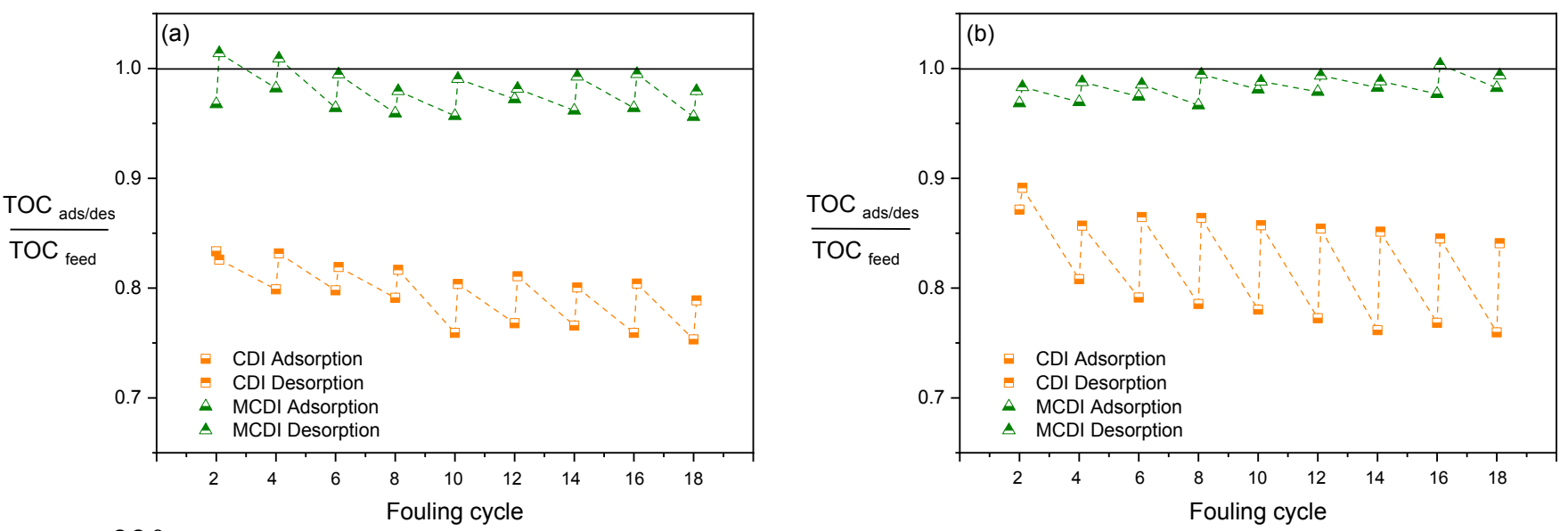

220

221

222

223

224

225 Due to the negative charge of the foulant materials, it is expected that the foulants adsorb on 226 the surface of the anion-exchange membrane as a result of the interaction between the foulant charge and the fixed charged groups within the membrane [26, 27]. Nonetheless, given that the performance metrics did not suffer significantly, it can be concluded that the fouling is reversible to some extent. In other words, some of the adsorbed organic species is removed by the shear force applied by the flow through the flow channel and/or during the desorption period. This is evidenced by TOC ratios of greater than unity in Figure 3. The polarity reversal in the case of MCDI helps to remove the temporarily attracted foulants from the surface of the membrane. In contrast to electrodialysis, where the flow direction of the charged species is continuously perpendicular to the IEM surface, in MCDI by reversing the cell voltage the flow
Fig. 3. Comparing the TOC content of the effluent over adsorption/desorption periods of CDI and MCDI, a) with a feed containing $8.5 \mathrm{mM} \mathrm{NaCl}, 0.5 \mathrm{mM} \mathrm{CaCl}_{2}$, and $60 \mathrm{mg} \mathrm{L}^{-1}$ of SA, b) with a feed containing $10 \mathrm{mM} \mathrm{NaCl}$ and $60 \mathrm{mg} \mathrm{L}^{-1}$ of $\mathrm{HA}$. 
behaviour has been reported for reversed-electrodialysis (EDR) where cleaning occurs by reversing the direction of the DC current or voltage $[28,29]$.

238

Small charged molecules such as organic acids can permeate through such ion exchange membranes[30, 31]. However, the foulants used here are much larger and so any diffusion through the membranes is very slow. Indeed, Chen et al.[11] could not observe either humic acid or alginate deposits on their carbon electrodes after 15 days of fouling at similar conditions to those used here. By placing the IEMs in front of the electrodes, the access of the foulant to the carbon material is very limited. Therefore, there is no physical attachment of organic materials to the carbon and hence no significant loss in charge efficiency.

A prolonged adsorption period might worsen the fouling in MCDI as the charged organic compound might be able to penetrate further into the membrane and therefore the cleaning by polarity reversal might not be sufficient. Chen et al.[11] used cycle times of 50-55 minutes and did observe losses in salt removal efficiency and charge consumption over 15 days.

\subsection{Effect of feed concentration in MCDI fouling with alginic acid}

Three sets of experiments were carried out to further study fouling of the MCDI cell with $\mathrm{SA} / \mathrm{Ca}^{2+}$ in $\mathrm{NaCl}$ solution. Initially at a SA concentration of $20 \mathrm{mg} \mathrm{L}^{-1}$, the concentration of calcium was increased from $0.05 \mathrm{mM}$ to $1 \mathrm{mM}$. The concentration of sodium was adjusted to

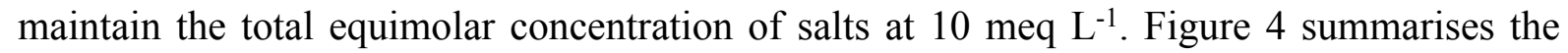
effect of calcium concentration, with replicate experiments shown for the case with $0.5 \mathrm{mM}$ to provide an indication of experimental variability. It is apparent that when increasing the calcium to alginate ratio, a more tenacious crosslinked alginate gel forms and this corresponds to a more significant drop in the adsorption of charged species [32]. However, the fouling layer appears conductive, as the charge efficiency is not compromised. Indeed, this charge efficiency actually appears to increase during the fouling run. This probably reflects changes in the conductivity measurement, firstly due to the addition of calcium to the feed solution at the beginning of the fouling test; and secondly, as calcium is preferentially adsorbed into the IEMs during the fouling test. Such preferential uptake of divalent ions such as calcium is well known[33, 34][35] and can impact on the electrical conductivity of both the solution and the membrane[33]. 

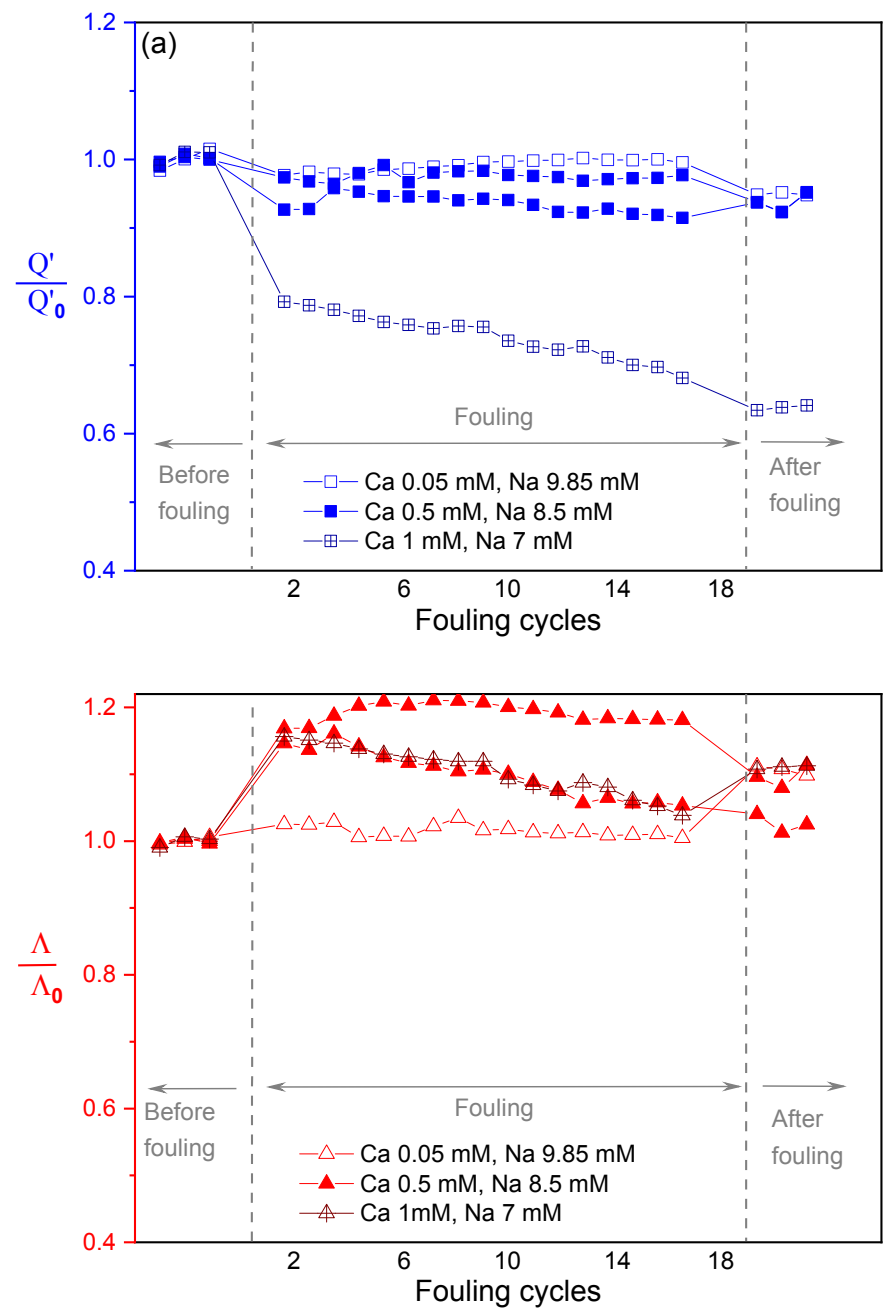

Fig. 4 Effect of calcium concentration on MCDI fouling. Fouling was carried out with a feed containing $10 \mathrm{meq} \mathrm{L}^{-1}$ salt and $20 \mathrm{mg} \mathrm{L}^{-1}$ of SA. Replicate runs are shown for the case with $0.5 \mathrm{mM}$ calcium as an indication of experimental variability.

272 Secondly, the concentration of alginate was varied from 20 to $100 \mathrm{mg} \mathrm{L}^{-1}$, but the concentration

273 of calcium was maintained at $0.5 \mathrm{mM}$, In this case, there was no consistent trends in the fouling 274 data, with all three concentrations resulting in minimal loss in either salt adsorption or charge 275 efficiency (data not shown). Similarly, in the last set of experiments, the concentration of SA and $\mathrm{Ca}^{2+}$ were increased proportionally. A feed containing $\left(20 \mathrm{mg} \mathrm{L}^{-1}\right.$ of $\mathrm{SA}+0.5 \mathrm{mM}$ of Ca$\left.{ }^{2+}\right)$ was compared with $\left(40 \mathrm{mg} \mathrm{L}^{-1}\right.$ of SA $\left.+1 \mathrm{mM} \mathrm{foa}^{2+}\right)$, and $\left(60 \mathrm{mg} \mathrm{L}^{-1}\right.$ of SA $+1.5 \mathrm{mM}$ of

$278 \mathrm{Ca}^{2+}$ ). Again, the extent of fouling was minimal for all three cases (Figure 5). The calcium to 279 alginate ratio in this case appears to provide only a weak gel that even at higher concentrations 280 is not able to reduce salt adsorption in the manner observed at higher ratios (Figure 4). 

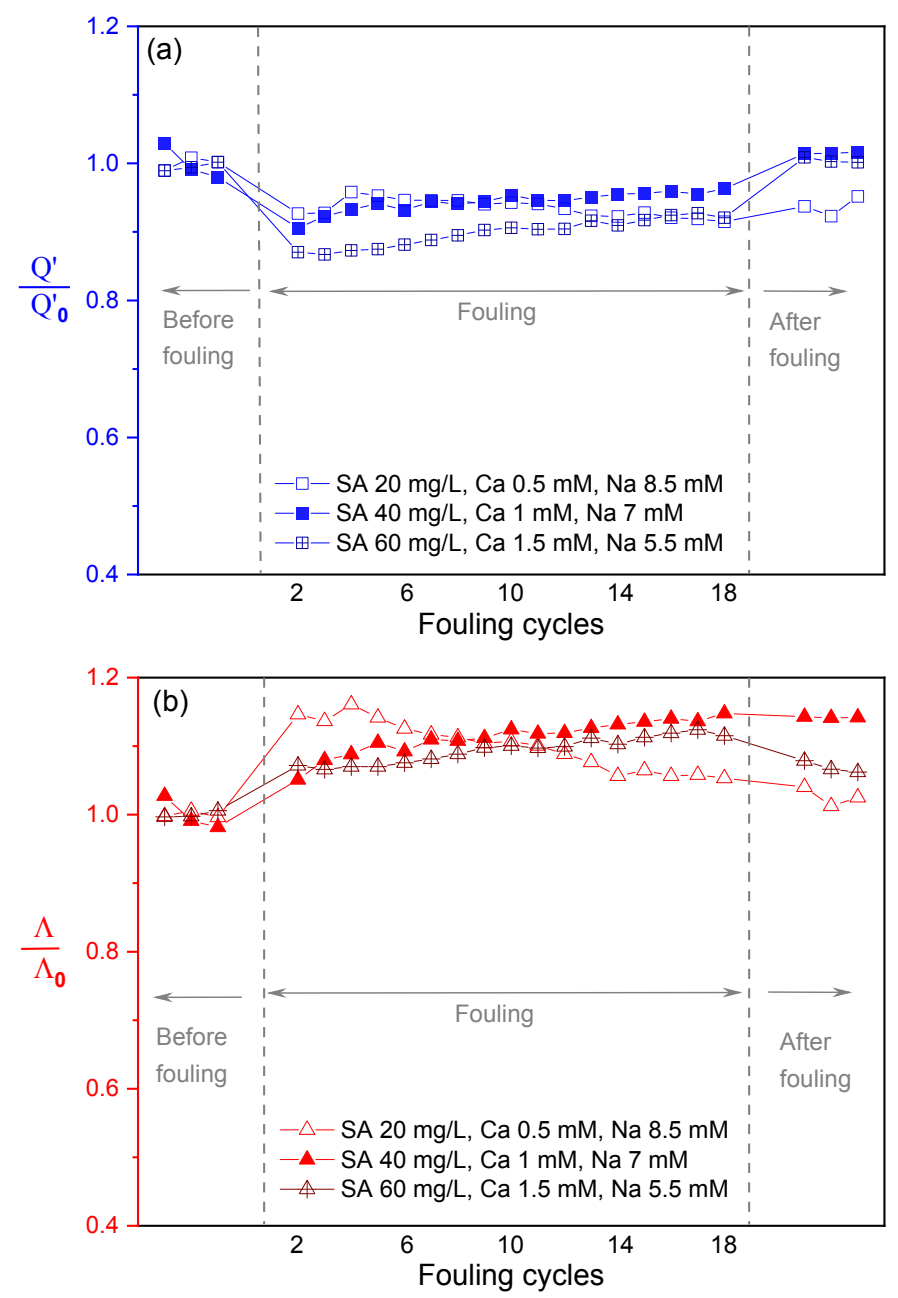

Fig. 5. Effect of a simultaneous increase of $\mathrm{SA}$ and $\mathrm{Ca}^{2+}$ concentrations on MCDI fouling.

\subsection{Cleaning limitations in CDI and MCDI}

286 In CDI fouling studies, Mossad et al. [5], Zhang et al. [6] and Wang et al. [36] all suggested

287 the use of alkaline solutions to remove the organic foulant. Hence, following the fouling

288 experiments performed on the CDI cell with $60 \mathrm{mg} \mathrm{L}^{-1} \mathrm{SA}$ and HA separately, cleaning with

289 alkaline solutions was performed to remove the negatively charged species from the surface of 290 the carbon. In the first section of cleaning, $\mathrm{NaOH}$ solution at $10 \mathrm{mM}(\mathrm{pH}=12)$ was used for

$291120 \mathrm{~min}$ followed by $\mathrm{NaOH}$ solution at $100 \mathrm{mM}(\mathrm{pH}=13)$ for $60-120 \mathrm{~min}$. This two step

292 cleaning process was used to determine the relative impact of cleaning at these two $\mathrm{pH}$ levels. 
293 The effluent was collected in containers over certain periods to measure the total concentration 294 of carbon removed. The result is shown in Fig. 6 and 7.
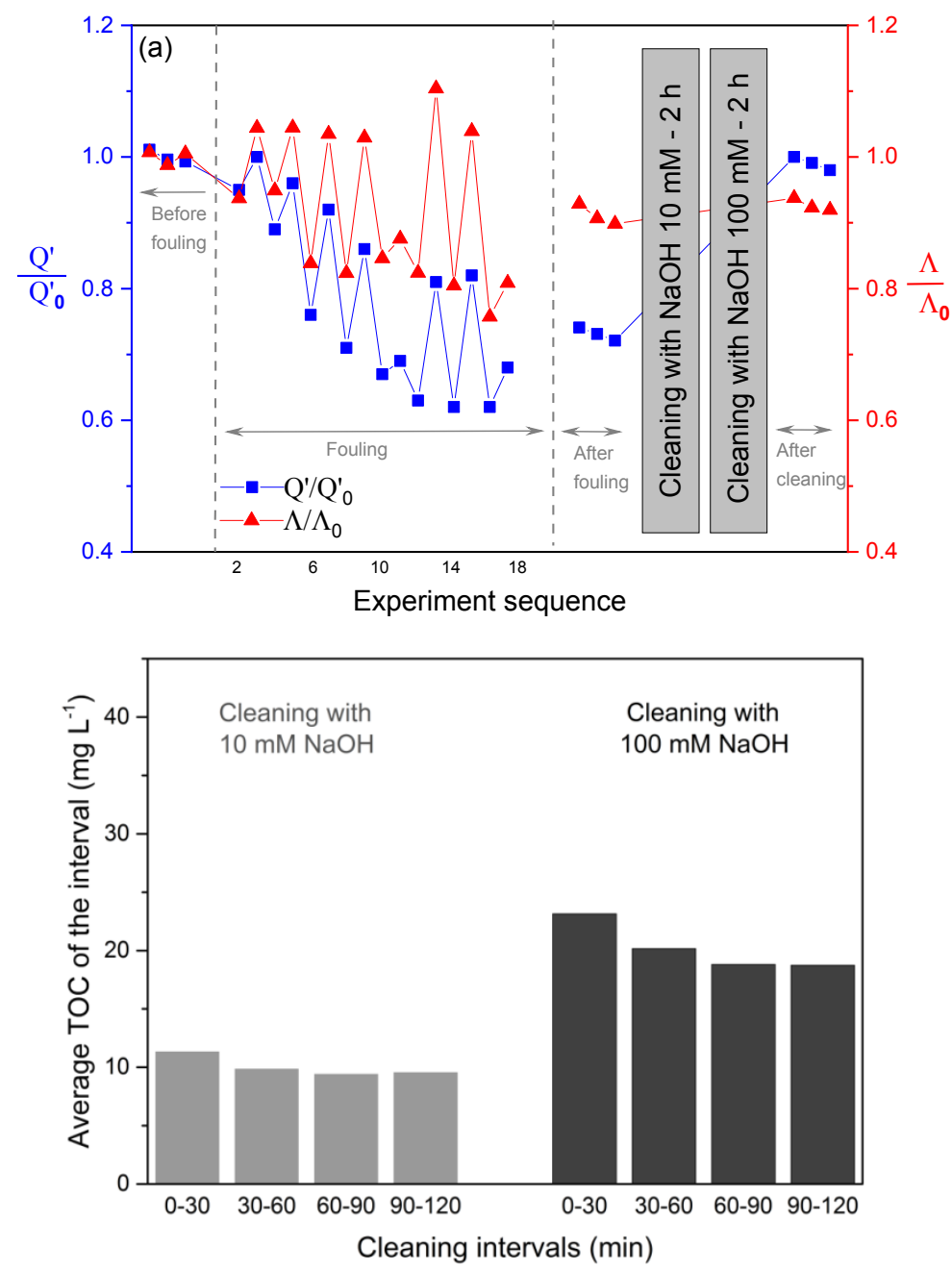

297 Fig. 6. Effect of cleaning fouled CDI with $\mathrm{NaOH}$ solutions, (a) fouling with SA followed by cleaning, (b) average TOC of the effluent during cleaning. 

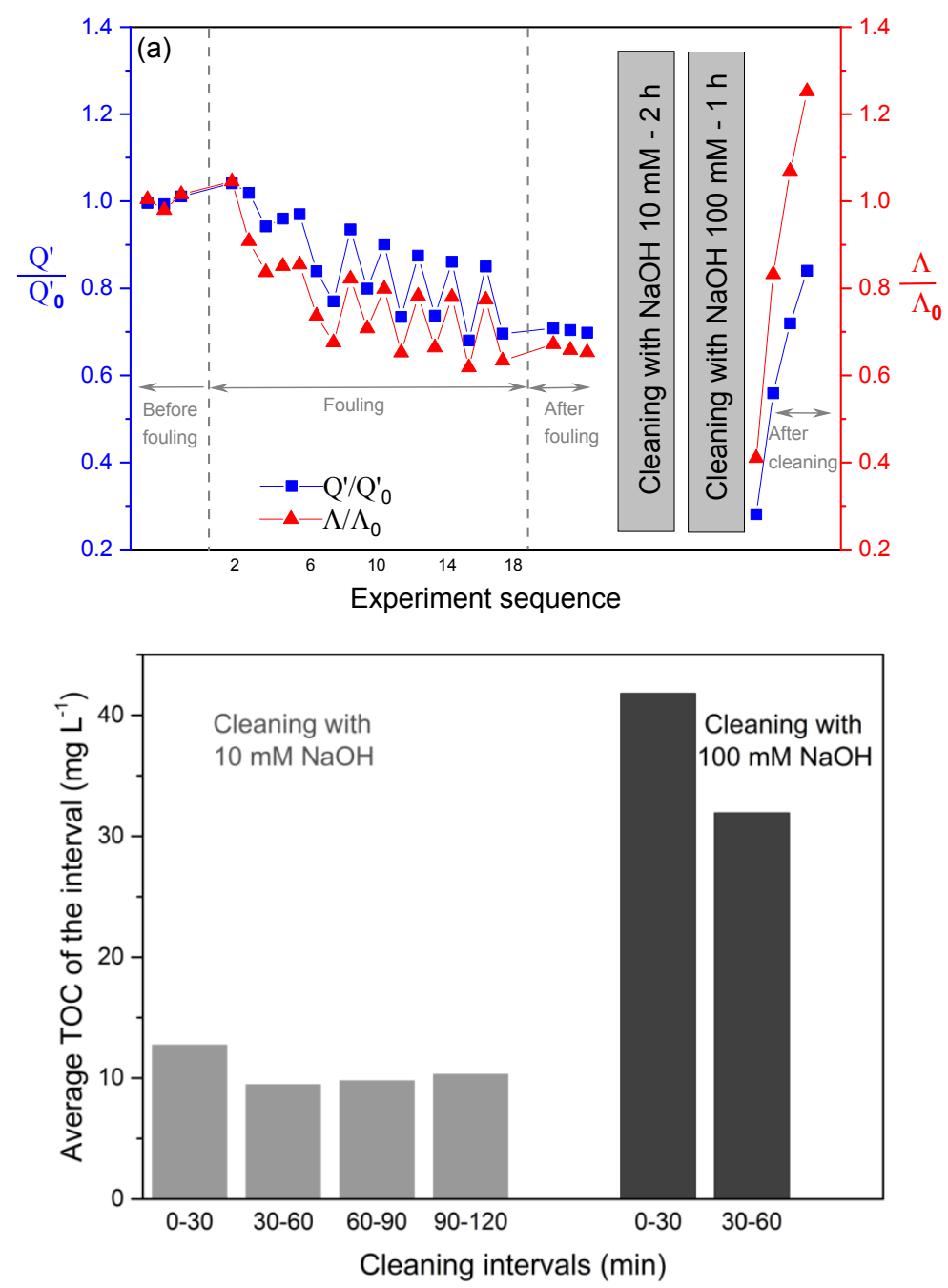

301 Fig. 7. Effect of cleaning fouled $\mathrm{CDI}$ with $\mathrm{NaOH}$ solutions, a) fouling with $\mathrm{HA}$ followed by cleaning, 302 b) average TOC of the effluent during cleaning.

304 In both cases, the alkali cleaning is effective in restoring the salt adsorption, although there is 305 a delay in recovery of this adsorption after HA fouling. However, it appears that the charge 306 efficiency is not recovered for the SA case, remaining at around $92 \%$ of the original value. 307 Conversely, the charge efficiency exceeds the initial value for the HA case. It is possible that 308 the use of the $\mathrm{NaOH}$ solution altered the carbon surface, in turn altering the extent of faradaic 309 reactions and thus causing these unexpected changes in charge efficiency.

310 Interestingly, the total amount of carbon collected over the cleaning step is $\sim 72 \mathrm{mg}$ in case of 311 fouling of SA and $\sim 70 \mathrm{mg}$ in case of fouling with HA. Given that the amount of carbon 312 accumulated during the fouling tests is limited to $18 \mathrm{mg}$ (see Fig. 3), the pronounced 
313 discrepancy begs the question as to whether or not the carbon electrode is being sacrificed 314 during the alkaline cleaning step. To investigate this, in another set of experiments, a pair of 315 unused carbon electrodes was inserted into the CDI cell. Once a steady state condition had been 316 obtained with a $10 \mathrm{mM} \mathrm{NaCl}$ solution, three different cleaning solutions were pumped through 317 the cell. Deionized water was used in between each step to remove the residual of the previous 318 solution. The experimental sequence and TOC result is summarised in Fig. 8.

319 Fig. 8 clearly demonstrates that cleaning the CDI cell with alkaline solution is not a practical 320 option due to the detrimental effect of $\mathrm{NaOH}$ on the carbon electrode. Other workers have 321 observed a detrimental effect of $\mathrm{NaOH}$ on PVDF membranes [37]. Thus, it is speculated that the PVDF, which is used as the binder in the electrode fabrication, is degraded by the alkaline solution. As a result, there is a gradual carbon loss during alkaline cleaning. On the other hand, acidic solutions have been shown to be ineffective in removing the negatively charged organic foulants $[5,36]$. Hence, it is recommended that potential organic foulants are removed prior to desalination with CDI. Alternatively, new binders that are alkali resistant might be used. For example, workers have grafted sulfonated polystyrene onto PVDF chains to improve the alkali resistance $[38,39]$. Electrodes that do not require a binder, such as carbon cloths, aerogels or flow electrodes provide another possible approach. A further option is to develop alternative cleaning processes.

331 We show in Section 3.1.2 that the extent of fouling is much more limited in MCDI. However, 332 in this case, alkaline solutions again cannot be used for cleaning because of the limited $\mathrm{pH}$ 333 tolerance range of the anion exchange membrane ( $\mathrm{pH} 0$ to 8 ). MCDI cleaning experiments 334 were not conducted as part of this work, as given the limited degree of fouling observed here, any change in performance would be within the experimental error. 

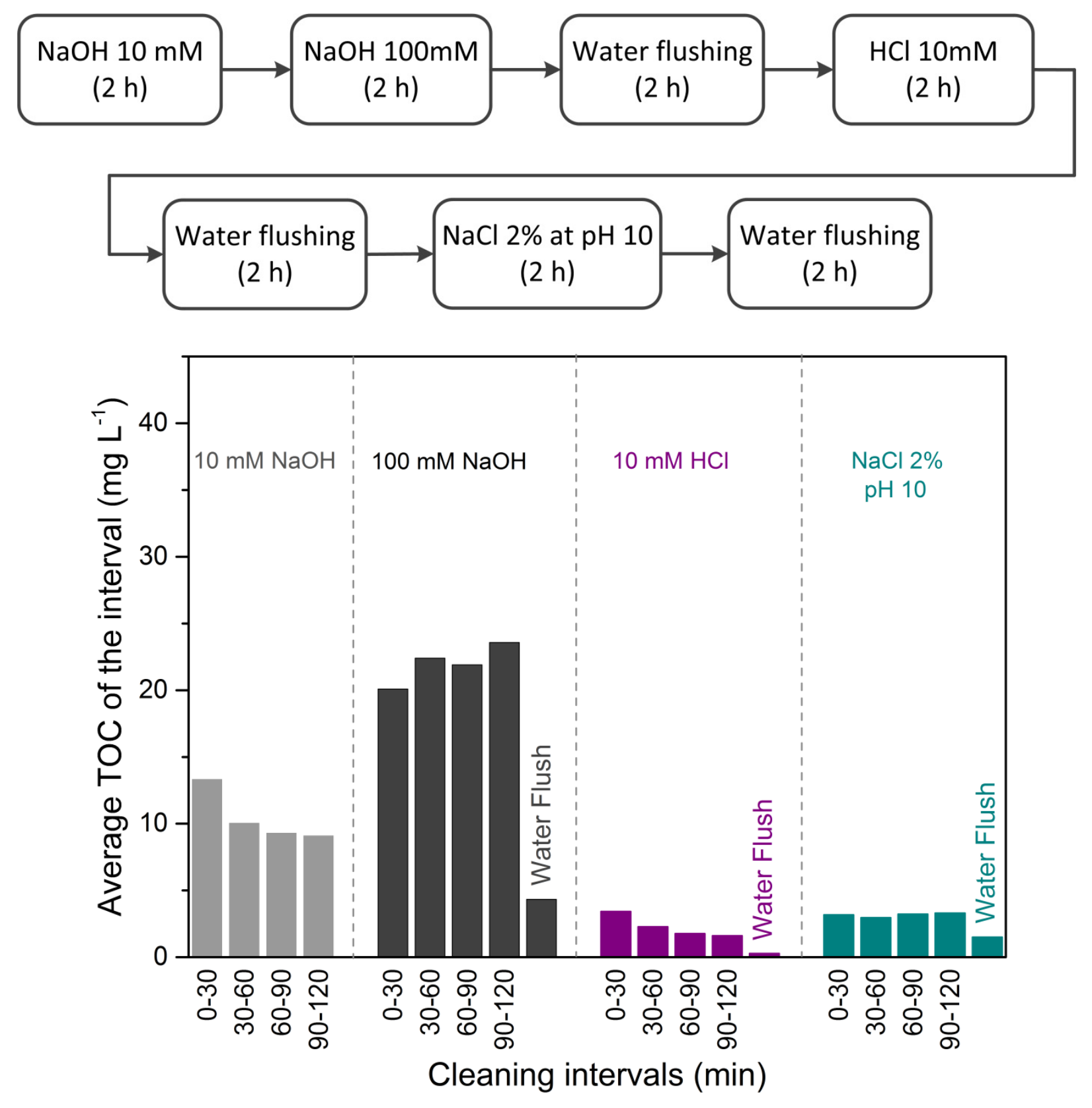

Fig. 8. Sequence of the cleaning and average TOC of the effluent.

\section{Conclusions}

344 The comprehensive fouling study performed here provides more details on the type of

345 interactions, degree of reversibility and effect of operational parameters in the case of humic

346 acid and sodium alginate fouling in CDI and MCDI. More significant fouling in CDI reflected

347 the strong covalent and electrostatic interactions between the activated carbon and the foulant.

348 Pore blockage, coverage of the adsorption sites, and surface charge change resulted in a fall in 
salt adsorption and charge efficiency. In the case of MCDI, however, the effect of fouling was more limited. Fouling was exacerbated by higher ratios of calcium to alginic acid, as has been observed by other workers.

Due to the negatively charged nature of the organic foulants, base solutions were used as the cleaning solutions to remove the fouling layer in the CDI cell. However, such alkali cleaning was shown to result in erosion of the activated carbon electrode. It is likely that it was the PVDF binder that was damaged and hence future work should focus on the development of alternative binder materials, alternate electrode designs that do not require a binder, or alternative cleaning solutions. Cleaning options were also limited for the MCDI cell, due to the limited $\mathrm{pH}$ operating range of the anion exchange membrane. These issues must be resolved if this technology is to be used in water systems where fouling agents are present.

\section{Acknowledgements}

Armineh Hassanvand acknowledges The University of Melbourne for the IPRS (International Postgraduate Research Scholarship) and APA (Australian Postgraduate Awards) scholarships, which are funded by the Australian Government. George Chen and Sandra Kentish acknowledge research funding from the Australian Research Council's Industrial Transformation Research Program (ITRP) scheme (Project Number IH120100005). The ARC Dairy Innovation Hub is a collaboration between The University of Melbourne, The University of Queensland and Dairy Innovation Australia Ltd.

\section{References}

[1] R. Zhao, S. Porada, P.M. Biesheuvel, A. van der Wal, Energy consumption in membrane capacitive deionization for different water recoveries and flow rates, and comparison with reverse osmosis, Desalination, 330 (2013) 35-41.

[2] A.A.M. Daifullah, B.S. Girgis, H.M.H. Gad, A study of the factors affecting the removal of humic acid by activated carbon prepared from biomass material, Colloids and Surfaces A: Physicochemical and Engineering Aspects, 235 (2004) 1-10.

[3] K. Yang, B. Xing, Adsorption of Organic Compounds by Carbon Nanomaterials in Aqueous Phase: Polanyi Theory and Its Application, Chem. Rev. (Washington, DC, U. S.), 110 (2010) 5989-6008.

[4] M.C. Lee, V.L. Snoeyink, J.C. Crittenden, Activated carbon adsorption of humic substances, Journal (American Water Works Association), 73 (1981) 440-446.

[5] M. Mossad, L. Zou, Study of fouling and scaling in capacitive deionisation by using dissolved organic and inorganic salts, Journal of hazardous materials, 244-245 (2013) 387393. 
[6] W. Zhang, M. Mossad, L. Zou, A study of the long-term operation of capacitive deionisation in inland brackish water desalination, Desalination, 320 (2013) 80-85. [7] E. Korngold, F. De Korosy, R. Rahav, M.F. Taboch, Fouling of anion-selective membranes in electrodialysis, Desalination, 8 (1970) 195-220.

[8] H.-J. Lee, S.-H. Moon, S.-P. Tsai, Effects of pulsed electric fields on membrane fouling in electrodialysis of $\mathrm{NaCl}$ solution containing humate, Sep. Purif. Technol., 27 (2002) 89-95.

[9] T. Xu, Ion exchange membranes: State of their development and perspective, J. Membr. Sci., 263 (2005) 1-29.

[10] M.-E. Langevin, L. Bazinet, Ion-exchange membrane fouling by peptides: A phenomenon governed by electrostatic interactions, Journal of Membrane Science, 369 (2011) 359-366. [11] L. Chen, C. Wang, S. Liu, Q. Hu, L. Zhu, C. Cao, Investigation of the long-term desalination performance of membrane capacitive deionization at the presence of organic foulants, Chemosphere, 193 (2018) 989-997. [12] Y.-J. Kim, J. Hur, W. Bae, J.-H. Choi, Desalination of brackish water containing oil compound by capacitive deionization process, Desalination, 253 (2010) 119-123. and design through experiment and modelling: Regeneration with brine and optimum residence time, Desalination, 417 (2017) 36-51.

[14] L.N. Sim, J. Gu, H.G.L. Coster, A.G. Fane, Quantitative determination of the electrical properties of $\mathrm{RO}$ membranes during fouling and cleaning processes using electrical impedance spectroscopy, Desalination, 379 (2016) 126-136.

405 [15] A. Widjaya, T. Hoang, G.W. Stevens, S.E. Kentish, A comparison of commercial reverse osmosis membrane characteristics and performance under alginate fouling conditions, Separation and Purification Technology, 89 (2012) 270-281.

408 [16] International Organization for Standardization ISO-5073. Brown coals and lignites409 determination of humic acids, (2013).

410 [17] A.J. Karabelas, A. Karanasiou, D.C. Sioutopoulos, Experimental study on the effect of polysaccharides on incipient membrane scaling during desalination, Desalination, 416 (2017) 106-121.

413 [18] M. Zhang, H. Lin, L. Shen, B.-Q. Liao, X. Wu, R. Li, Effect of calcium ions on fouling 414 properties of alginate solution and its mechanisms, Journal of Membrane Science, 525 (2017) 415 320-329.

416 [19] J. Wang, L. Bi, Y. Ji, H. Ma, X. Yin, Removal of humic acid from aqueous solution by 417 magnetically separable polyaniline: Adsorption behavior and mechanism, Journal of colloid 418 and interface science, 430 (2014) 140-146.

419 [20] M.S. Rauthula, V.C. Srivastava, Studies on adsorption/desorption of nitrobenzene and humic acid onto/from activated carbon, Chemical Engineering Journal, 168 (2011) 35-43. [21] J. Duan, F. Wilson, N. Graham, J.H. Tay, Adsorption of humic acid by powdered activated carbon in saline water conditions, Desalination, 151 (2003) 53-66.

[22] G. Newcombe, Activated carbon and soluble humic substances: adsorption, desorption, and surface charge effects, Journal of colloid and interface science, 164 (1994) 452-462. [23] K. Yang, L. Zhu, B. Xing, Adsorption of Polycyclic Aromatic Hydrocarbons by Carbon Nanomaterials, Environ. Sci. Technol., 40 (2006) 1855-1861.

[24] S. Lee, W.S. Ang, M. Elimelech, Fouling of reverse osmosis membranes by hydrophilic organic matter: implications for water reuse, Desalination, 187 (2006) 313-321.

[25] M.B. Stewart, D.T. Myat, M. Kuiper, R.J. Manning, S.R. Gray, J.D. Orbell, A structural basis for the amphiphilic character of alginates - Implications for membrane fouling, Carbohydrate Polymers, 164 (2017) 162-169. organic substances, Desalination, 128 (2000) 91-102. 
[27] D.H. Kim, S.-H. Moon, J. Cho, Investigation of the adsorption and transport of natural organic matter (NOM) in ion-exchange membranes, Desalination, 151 (2003) 11-20. [28] W.E. Katz, The electrodialysis reversal (EDR) process, Desalination, 28 (1979) 31-40. [29] S. Mikhaylin, L. Bazinet, Fouling on ion-exchange membranes: Classification, characterization and strategies of prevention and control, Advances in colloid and interface science, 229 (2016) 34-56.

440 [30] C.S. López-Garzón, A.J.J. Straathof, Recovery of carboxylic acids produced by 441 fermentation, Biotechnology Advances, 32 (2014) 873-904.

442 [31] G.Q. Chen, F.I.I. Eschbach, M. Weeks, S.L. Gras, S.E. Kentish, Removal of lactic acid 443 from acid whey using electrodialysis, Separation and Purification Technology, 158 (2016) 230444237.

445 [32] S. Lee, M. Elimelech, Salt cleaning of organic-fouled reverse osmosis membranes, Water 446 Res., 41 (2007) 1134-1142.

447 [33] E. Ayala-Bribiesca, M. Araya-Farias, G. Pourcelly, L. Bazinet, Effect of concentrate 448 solution $\mathrm{pH}$ and mineral composition of a whey protein diluate solution on membrane fouling 449 formation during conventional electrodialysis, Journal of Membrane Science, 280 (2006) 790450801.

451 [34] A. Hassanvand, G.Q. Chen, P.A. Webley, S.E. Kentish, A comparison of multicomponent 452 electrosorption in capacitive deionization and membrane capacitive deionization, Water 453 Research, 131 (2018) 100-109.

454 [35] F.L.T. Shee, P. Angers, L. Bazinet, Microscopic approach for the identification of cationic 455 membrane fouling during cheddar cheese whey electroacidification, Journal of colloid and 456 interface science, 322 (2008) 551-557.

457 [36] C. Wang, H. Song, Q. Zhang, B. Wang, A. Li, Parameter optimization based on capacitive 458 deionization for highly efficient desalination of domestic wastewater biotreated effluent and 459 the fouled electrode regeneration, Desalination, 365 (2015) 407-415.

460 [37] M.F. Rabuni, N.M. Nik Sulaiman, M.K. Aroua, N.A. Hashim, Effects of Alkaline 461 Environments at Mild Conditions on the Stability of PVDF Membrane: An Experimental 462 Study, Ind. Eng. Chem. Res., 52 (2013) 15874-15882.

463 [38] N. Daems, S. Milis, R. Verbeke, A. Szymczyk, P.P. Pescarmona, I.F.J. Vankelecom, High464 performance membranes with full $\mathrm{pH}$-stability, RSC Advances, 8 (2018) 8813-8827.

465 [39] S. Holmberg, T. Lehtinen, J. Näsman, D. Ostrovskii, M. Paronen, R. Serimaa, F. 466 Sundholm, G. Sundholm, L. Torell, M. Torkkeli, Structure and properties of sulfonated poly 467 [(vinylidene fluoride)-g-styrene] porous membranes, Journal of Materials Chemistry, 6 (1996) $468 \quad 1309-1317$. 